\title{
Ambulatory pulse pressure, decreased nocturnal blood pressure reduction and progression of nephropathy in type 2 diabetic patients
}

\author{
S. T. Knudsen • E. Laugesen • K. W. Hansen • T. Bek • \\ C. E. Mogensen • P. L. Poulsen
}

Received: 24 September 2008 / Accepted: 23 December 2008 / Published online: 29 January 2009

(C) Springer-Verlag 2009

\begin{abstract}
Aims/hypothesis We followed type 2 diabetic patients over a long period to evaluate the predictive value of ambulatory pulse pressure (PP) and decreased nocturnal BP reduction (non-dipping) for nephropathy progression.

Methods Type 2 diabetic patients $(n=112)$ were followed for an average of 9.5 (range 0.5-14.5) years. At baseline, all patients underwent $24 \mathrm{~h}$ ambulatory BP measurement. Urinary albumin excretion rate was evaluated by three urinary albumin:creatinine ratio measurements at baseline and follow-up.

Results At baseline, patients who subsequently progressed to a more advanced nephropathy stage $(n=35)$ had reduced diastolic night/day BP variation and higher 24 h systolic BP and PP values; they also had more advanced nephropathy and were more likely to smoke than those with no progression of nephropathy $(n=77)$. In a Cox regression analysis, independent predictors of nephropathy progression were $24 \mathrm{~h}$ PP $(p<0.01)$, diastolic night:day $\mathrm{BP}$ ratio $(p=0.02)$ and smoking $(p=0.02)$. The adjusted hazards ratio $(95 \%$ CI) for each mmHg increment in $24 \mathrm{~h}$ PP was 1.04 (1.01$1.07)$, whereas the adjusted hazards ratio $(95 \% \mathrm{CI})$ for each
\end{abstract}

S. T. Knudsen $(\bowtie) \cdot$ E. Laugesen $\cdot$ C. E. Mogensen $\cdot$ P. L. Poulsen Medical Department M (Diabetes and Endocrinology),

Aarhus University Hospital,

Nørrebrogade 44,

8000 Aarhus C, Denmark

e-mail: stk@dadlnet.dk

K. W. Hansen

Department of Internal Medicine, Regional Hospital Silkeborg,

Silkeborg, Denmark

T. Bek

Department of Ophthalmology, Aarhus University Hospital,

Aarhus, Denmark
$1 \%$ increase in diastolic night:day BP ratio was $1.06(1.01-$ $1.11)$. Only one of 33 patients $(3.0 \%)$ with both a diastolic night:day $\mathrm{BP}$ ratio and a $24 \mathrm{~h}$ PP below the median progressed, whereas 17 of 32 patients $(53.1 \%)$ with both a diastolic night:day BP ratio and a $24 \mathrm{~h}$ PP equal to or above the median progressed to a more advanced nephropathy stage $(p<0.001)$.

Conclusions/interpretation Ambulatory PP, impaired nocturnal BP decline and smoking are strong, independent predictors of nephropathy progression in type 2 diabetic patients.

Keywords Albuminuria Ambulatory blood pressure . Hypertension · Nephropathy $\cdot$ Non-dipping $\cdot$ Pulse pressure
Abbreviations
AHT Antihypertensive therapy
AMBP Ambulatory blood pressure
PP Pulse pressure
UAE Urinary albumin excretion rate

\section{Introduction}

An elevated pulse pressure (PP) is strongly associated with micro- [1-5] as well as macrovascular [1, 6-8] complications in type 2 diabetic patients. In a large observational study including 954 elderly type 2 diabetic patients [9], ambulatory PP was a strong and independent predictor of progression of nephropathy during a 2 year follow-up period. At present, no studies on the long-term predictive value of ambulatory PP for nephropathy progression in patients with type 2 diabetes have been published. 
Impaired nocturnal BP decline ('non-dipping') is another BP abnormality that has been associated with micro- [1, 10-17] and macrovascular [1, 18] complications in type 1 and type 2 diabetic patients. In a recently published 3 year follow-up study in elderly patients with type 2 diabetes [19], patients with a reversed diurnal BP rhythm (nocturnal BP 'risers') had an increased risk of nephropathy progression compared with those who had a normal reduction in BP during the night ('dippers'). Data on the long-term prognostic significance of blunted circadian BP variation for progression of nephropathy in type 2 diabetic patients are sparse.

Hence, the aim of the present study was to evaluate the predictive value of $24 \mathrm{~h}$ ambulatory PP and diurnal BP variation for progression of nephropathy in type 2 diabetic patients in a long-term follow-up study.

\section{Methods}

Patients We randomly selected 118 type 2 diabetic patients from our outpatients clinic from March 1993 through October 2000 and included them in the study. Cross-sectional data from a subgroup of these patients have previously been published [1]. Patients were followed for a mean of 9.5 (range 0.5-14.5) years until death or until 1 April 2008. Six patients were excluded due to incomplete $24 \mathrm{~h}$ ambulatory blood pressure (AMBP) measurement (four patients) or migration (two patients), thus leaving 112 patients with available follow-up data.

All patients included in the study were of white ethnicity. The diagnosis of diabetes was established according to WHO criteria. Type 2 diabetes was defined as: (1) onset of diabetes after the age of 30 years; (2) no need for insulin treatment for $\geq 1$ year after the diagnosis of diabetes; and (3) no history of ketoacidosis. Patients were classified as non-smokers (without daily use of tobacco for the preceding year) or smokers (daily use of tobacco). All patients gave their written informed consent to participate. The study adhered to the tenets of the Declaration of Helsinki and was approved by the local committee for biomedical ethics.

Twenty-four hour AMBP measurements The $24 \mathrm{~h}$ AMBP was measured by an oscillometric technique with Spacelabs 90202 and 90207 devices (Spacelabs, Redmond, WA, USA) validated according to the British Hypertension Society protocol [20]. Spacelabs 90202 obtained readings every $20 \mathrm{~min}$ between 06:00 and 00:00 hours and once hourly between 00:00 and 06:00 hours, whereas Spacelabs 90207 measured at $20 \mathrm{~min}$ intervals throughout the $24 \mathrm{~h}$ period. Measurements were performed during a day with normal activities at home or at work. Individually reported sleeping times were used in the calculation of day and night $\mathrm{BP}$. If more than $3 \mathrm{~h}$ were missing, the patient was excluded (four patients). Nocturnal BP dipping was evaluated by systolic and diastolic night:day BP ratios, presented as percentages, calculated by dividing night-time BP (average of the hourly averages over the night-time period) by daytime BP (average of the hourly averages over the day-time period) and multiplying this value by 100 . Office BP was measured with a Hawksley random zero sphygmomanometer (Hawksley, Sussex, UK). The mean of three measurements was calculated.

Nephropathy classification Urinary albumin concentration was determined by an immunoturbidimetric method (Roche Diagnostics, Basel, Switzerland). The urinary albumin excretion (UAE) was evaluated by albumin:creatinine ratios in three samples of morning urine at baseline as well as at follow-up. Patients were classified as normo-, micro- or macroalbuminuric when at least two of three samples had urinary albumin:creatinine ratios of $<2.5 \mathrm{mg} / \mathrm{mmol}$ (men) and $<3.5 \mathrm{mg} / \mathrm{mmol}$ (women), 2.5 to $25 \mathrm{mg} / \mathrm{mmol}$ (men) and 3.5 to $35 \mathrm{mg} / \mathrm{mmol}$ (women), or $>25 \mathrm{mg} / \mathrm{mmol}$ (men) and $>35 \mathrm{mg} / \mathrm{mmol}$ (women), respectively [21]. In patients with normoalbuminuria at baseline, progression of nephropathy was defined as the development of stable micro- or macroalbuminuria. In patients with micro- or macroalbuminuria at baseline, progression was defined as the development of stable macroalbuminuria, or a doubling of plasma creatinine level or development of end-stage renal failure, respectively [22-24].

Eye examinations In each eye a standard photograph of 60 degrees was taken. Each photograph was evaluated independently by two experienced graders. Patients were classified as having no, mild (grade 2) or advanced (grades 3-6) retinopathy as previously described [1].

Laboratory analyses $\mathrm{HbA}_{1 \mathrm{c}}$ was determined by highperformance liquid chromatography (non-diabetic range 4.4 to $6.4 \%$ ). Total cholesterol, HDL-cholesterol and triacylglycerol were analysed using an enzymatic colorimetric method (Cobas Integra 700; Roche). LDL-cholesterol was calculated from the Friedewald equation: LDL-cholesterol=total cholesterol - HDL-cholesterol - triacylglycerol $\times 0.45$.

Statistical analyses All variables were tested for normal distribution using the Kolmogorov-Smirnov non-parametric test. UAE and plasma creatinine level were logarithmically transformed prior to analysis in order to obtain normal distribution. Results are expressed as means \pm SD (normally distributed variables) or as medians with interquartile range for skewed data. Differences between groups at baseline were tested by the Student's $t$ test. For non-continuous 
variables, the $\chi^{2}$ test with Yates' correction was used. The predictive value of baseline variables for nephropathy progression is presented as HRs with $95 \%$ CIs.

The predictive value of baseline variables for nephropathy progression was evaluated by Cox proportional hazards multiple regression analyses. The analyses were performed with backwards selection including the following baseline variables that were significant at the 0.10 level in a bivariate analysis (log-rank test): smoking, plasma creatinine, $24 \mathrm{~h}$ systolic BP, $24 \mathrm{~h}$ PP and diastolic night:day $\mathrm{BP}$ ratio. In addition, sex, age, duration, baseline UAE and $\mathrm{HbA}_{1 \mathrm{c}}$ were included in the model because of their biologically plausible association with nephropathy progression. The following variables were excluded: baseline antihypertensive and glucose-lowering treatment modality, history of macrovascular disease, retinopathy severity, height, BMI, total cholesterol and HDL- and LDL-cholesterol, triacylglycerol, office BP values, $24 \mathrm{~h}$ diastolic AMBP values and systolic night:day BP ratio.

Data were analysed using SPSS (version 15.0) statistical software (Chicago, IL, USA). A two-tailed $p$ value of less than 0.05 was considered statistically significant.

\section{Results}

Baseline clinical and laboratory characteristics of study participants are given in Table 1. During follow-up, 35 (19 of 71 patients with normo-, seven of 26 patients with micro-, and nine of 15 patients with macroalbuminuria) of 112 patients progressed to a more advanced stage of nephropathy. All patients progressing from normo- to microor from micro- to macroalbuminuria had an increase in UAE of at least $25 \%$. Patients who subsequently progressed to a more advanced nephropathy stage tended to be older, had a slightly longer duration of diabetes, were more likely to be treated with insulin and tended to have more advanced retinopathy and macrovascular disease, higher office BP values, poorer glycaemic control and a higher plasma creatinine level than those with no progression of nephropathy $(n=77)$. However, these differences were not statistically significant. The number of patients on antihypertensive therapy (AHT) at baseline was similar for those with and those without progression of nephropathy. Moreover, night:day BP ratios did not differ between subgroups of AHT (data not shown).

In contrast, among the patients who progressed to a more advanced nephropathy stage there was a significant preponderance of smokers and patients with a more advanced degree of nephropathy at baseline. Likewise, diastolic night:day BP ratio and $24 \mathrm{~h}$ systolic BP and PP, but not $24 \mathrm{~h}$ diastolic BP, were significantly higher in the group who subsequently progressed to a more advanced
Table 1 Baseline clinical and laboratory characteristics of 112 type 2 diabetic patients without (non-progressors) or with progression (progressors) of nephropathy at follow-up

\begin{tabular}{|c|c|c|c|}
\hline Characteristic & $\begin{array}{l}\text { Non- } \\
\text { progressors } \\
(n=77)\end{array}$ & $\begin{array}{l}\text { Progressors } \\
(n=35)\end{array}$ & $p$ value \\
\hline Sex (men/women) & $45 / 32$ & $23 / 12$ & 0.53 \\
\hline Age (years) & $57 \pm 10$ & $59 \pm 8$ & 0.21 \\
\hline $\begin{array}{l}\text { Known duration of } \\
\text { diabetes (years) }\end{array}$ & $6 \pm 7$ & $8 \pm 8$ & 0.19 \\
\hline Antihypertensive treatment & 40 & 19 & 0.84 \\
\hline ACE inhibitor/ARB & 20 & 11 & 0.65 \\
\hline Beta-blocker & 13 & 4 & 0.58 \\
\hline Calcium channel blocker & 16 & 13 & 0.10 \\
\hline Diuretic & 16 & 8 & 0.81 \\
\hline Glucose-lowering treatment & & & 0.05 \\
\hline Diet & 30 & 6 & \\
\hline Oral agent & 34 & 18 & \\
\hline Insulin & 13 & 11 & \\
\hline Smoking & 19 & 17 & 0.01 \\
\hline $\begin{array}{l}\text { History of macrovascular } \\
\text { disease }\end{array}$ & 19 & 13 & 0.18 \\
\hline Retinopathy & & & 0.17 \\
\hline None & 43 & 17 & \\
\hline Mild & 25 & 9 & \\
\hline Advanced & 9 & 9 & \\
\hline Nephropathy & & & 0.02 \\
\hline Normoalbuminuria & 52 & 19 & \\
\hline Microalbuminuria & 19 & 7 & \\
\hline Macroalbuminuria & 6 & 9 & \\
\hline BMI $\left(\mathrm{kg} / \mathrm{m}^{2}\right)$ & $29 \pm 5$ & $30 \pm 5$ & 0.79 \\
\hline $\mathrm{HbA}_{1 \mathrm{c}}(\%)$ & $8.2 \pm 1.7$ & $8.8 \pm 2.0$ & 0.13 \\
\hline $\begin{array}{l}\text { Plasma creatinine } \\
(\mu \mathrm{mol} / \mathrm{l})\end{array}$ & $76(66-87)$ & $78(67-99)$ & 0.08 \\
\hline $\begin{array}{l}\text { Urinary albumin: } \\
\text { creatinine ratio } \\
(\mathrm{mg} / \mathrm{mmol})\end{array}$ & $1.6(0.8-4.0)$ & $2.8(1.5-23.8)$ & 0.59 \\
\hline Total cholesterol $(\mathrm{mmol} / \mathrm{l})$ & $5.9 \pm 1.0$ & $5.8 \pm 1.7$ & 0.71 \\
\hline HDL-cholesterol (mmol/l) & $1.2 \pm 0.3$ & $1.2 \pm 0.4$ & 0.66 \\
\hline Triacylglycerol (mmol/l) & $2.5 \pm 2.2$ & $2.4 \pm 1.3$ & 0.68 \\
\hline $\begin{array}{l}\text { Office systolic blood } \\
\text { pressure }(\mathrm{mmHg})\end{array}$ & $155 \pm 23$ & $161 \pm 20$ & 0.17 \\
\hline $\begin{array}{l}\text { Office diastolic blood } \\
\text { pressure }(\mathrm{mmHg})\end{array}$ & $92 \pm 10$ & $93 \pm 17$ & 0.63 \\
\hline Office PP (mmHg) & $62 \pm 18$ & $68 \pm 16$ & 0.16 \\
\hline $\begin{array}{l}24 \mathrm{~h} \text { systolic blood } \\
\text { pressure }(\mathrm{mmHg})\end{array}$ & $138 \pm 13$ & $149 \pm 21$ & $<0.01$ \\
\hline $\begin{array}{l}24 \mathrm{~h} \text { diastolic blood } \\
\text { pressure }(\mathrm{mmHg})\end{array}$ & $81 \pm 9$ & $85 \pm 12$ & 0.09 \\
\hline 24 h PP (mmHg) & $56 \pm 10$ & $64 \pm 14$ & $<0.001$ \\
\hline $\begin{array}{l}\text { Systolic night:day blood } \\
\text { pressure ratio }(\%)\end{array}$ & $89.4 \pm 7.8$ & $91.7 \pm 7.3$ & 0.14 \\
\hline $\begin{array}{l}\text { Diastolic night:day blood } \\
\text { pressure ratio }(\%)\end{array}$ & $84.8 \pm 8.5$ & $88.9 \pm 7.6$ & 0.01 \\
\hline
\end{tabular}

Values are $n$, mean $\pm \mathrm{SD}$ or median (interquartile range) $\mathrm{ARB}$, angiotensin 2 receptor antagonist 
nephropathy stage. The proportion of patients who exhibited progression of nephropathy according to baseline smoking status and $24 \mathrm{~h}$ systolic BP, $24 \mathrm{~h}$ PP and diastolic night:day ratio below the median or equal to or above the median is presented in Table 2.

At baseline, smokers and non-smokers had similar diastolic night:day BP ratios and $24 \mathrm{~h}$ PP values $(p>0.3$ for both comparisons). Similarly, diastolic night:day BP ratios and $24 \mathrm{~h}$ PP values did not correlate statistically $\left(r^{2}=\right.$ $0.004, p=0.48)$. The predictive value of combining the two BP indices is illustrated in Fig. 1. Only one of 33 patients $(3.0 \%)$ with a diastolic night:day BP ratio and a $24 \mathrm{~h}$ PP below the median progressed, whereas 17 of 32 patients (53.1\%) with both a diastolic night:day BP ratio and a $24 \mathrm{~h}$ PP equal to or above the median progressed to a more advanced nephropathy stage $(p<0.001)$.

In unadjusted bivariate analyses, $24 \mathrm{~h}$ PP was the baseline variable most strongly correlated with nephropathy progression; $46.3 \%$ of patients with a $24 \mathrm{~h}$ PP equal to or above the median value of $57.5 \mathrm{mmHg}$ exhibited progression of nephropathy, whereas only $16 \%$ of patients with a $24 \mathrm{~h}$ PP below the median value subsequently progressed (log-rank test for differences between groups, $p<0.001$ ) (Fig. 2). Cox proportional hazards models were used to test which baseline variables were independently predictive of subsequent nephropathy progression. The final model included sex, age, duration of diabetes, smoking, baseline UAE, $\mathrm{HbA}_{1 \mathrm{c}}$, plasma creatinine, $24 \mathrm{~h}$ systolic BP, $24 \mathrm{~h}$ PP and diastolic night:day BP ratio. Independent predictors of nephropathy progression were smoking (HR $2.48,95 \%$ CI 1.19-5.17, $p=0.02$ ), $24 \mathrm{~h}$ PP (HR 1.04 [for each $\mathrm{mmHg}$ increase], CI 1.01-1.07, $p<0.01)$ and diastolic night:day BP ratio (HR 1.05 [for 1\% increase], 95\% CI 1.01-1.07, $p=$ 0.02 ); the other variables in the model did not have a

Table 2 Percentage of patients with progression of nephropathy at follow-up according to categories of baseline variables (below the median value or equal to or above the median value)

\begin{tabular}{lcc}
\hline Variable & $\begin{array}{c}\text { Progression of } \\
\text { nephropathy (\%) }\end{array}$ & $p$ value \\
\hline Smoking & & 0.01 \\
$\quad$ No & 24.7 & \\
Yes & 47.2 & \\
24 h systolic blood pressure & & 0.02 \\
$<138.3 \mathrm{mmHg}$ & 19.6 & \\
$\geq 138.3 \mathrm{mmHg}$ & 41.1 & \\
$24 \mathrm{~h} \mathrm{PP}$ & & $<0.001$ \\
$\quad<57.5 \mathrm{mmHg}$ & 16.1 & \\
$\geq 57.5 \mathrm{mmHg}$ & 46.4 & \\
Diastolic night:day blood pressure ratio & & \\
$\quad<85.0 \%$ & 17.9 & \\
$\geq 85.0 \%$ & 44.6 & \\
\hline
\end{tabular}

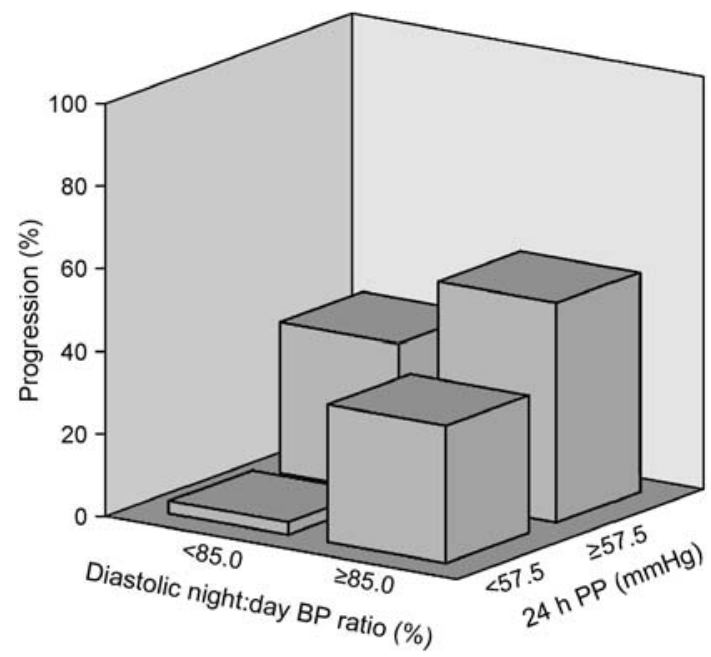

Fig. 1 Three-dimensional graph of the proportion of type 2 diabetic patients with progression of nephropathy according to categories of diastolic night:day BP ratio $(<85.0 \%$ or $\geq 85.0 \%$, the median value) and $24 \mathrm{~h}$ ambulatory $\mathrm{PP}(<57.5 \mathrm{mmHg}$ or $\geq 57.5 \mathrm{mmHg}$, the median value). $p<0.001$ ( $\chi^{2}$ test with Yates' correction)

significant independent predictive value for nephropathy progression.

\section{Discussion}

In this prospective observational study with a follow-up period of 9.5 years, high $24 \mathrm{~h}$ PP and impaired nocturnal diastolic blood pressure decline were both strong and independent predictors of nephropathy progression, thus confirming hypotheses generated from previous cross-

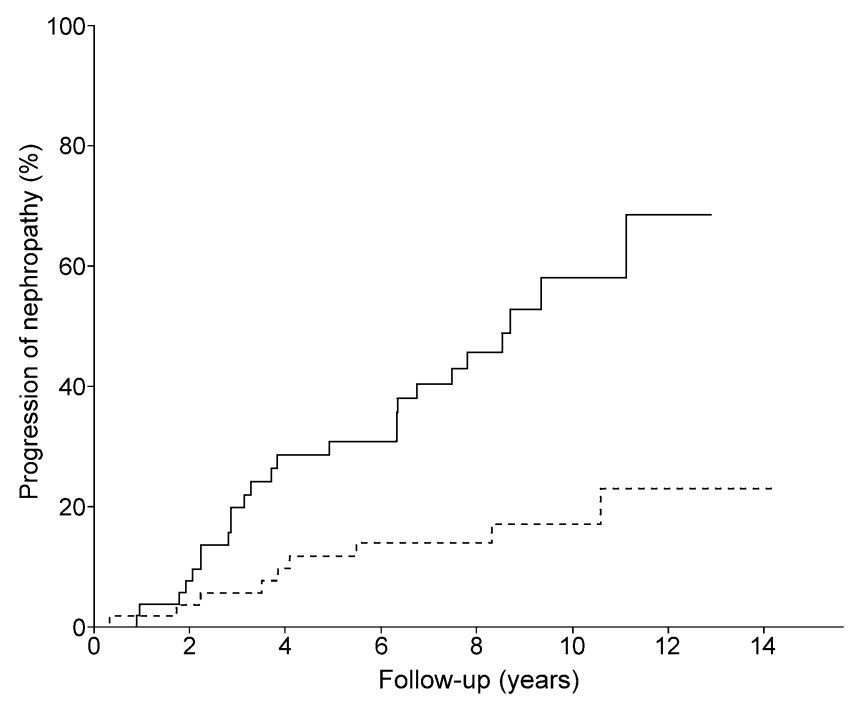

Fig. 2 Progression of nephropathy in type 2 diabetic patients with a $24 \mathrm{~h}$ ambulatory PP below (dashed line, $n=56$ ) or equal to or above (solid line, $n=56$ ) the median $(57.5 \mathrm{mmHg}) . p<0.001$ (log-rank test) 
sectional and short-term observational studies. In the proportional hazards analysis, a $1 \mathrm{mmHg}$ increase in $24 \mathrm{~h}$ $\mathrm{PP}$ and a $1 \%$ increase in diastolic night:day BP ratio conferred an increased risk of nephropathy progression of 4 and $5 \%$, respectively, whereas smoking more than doubled the risk of nephropathy progression, even after adjustment for multiple other potential risk factors.

During the last decade, numerous studies have established PP as a strong, independent predictor of cardiovascular morbidity and mortality in non-diabetic patients [2530]. In 2002, we published baseline data from the middleaged Danish type 2 diabetic patients participating in the present follow-up study [1]. In this cross-sectional study, we were the first to demonstrate strong associations between ambulatory PP values and micro- and macrovascular complications; in particular, the association between PP and albuminuria was very strong [1]. Although the crosssectional design did not allow any firm conclusions regarding causality, we hypothesised that $\mathrm{PP}$ could be a risk factor for the progression of albuminuria in this patient group. Subsequently, several studies have associated an elevated PP with both micro- $[3,5]$ and macrovascular [68] complications in diabetic patients.

In 2006, Palmas et al. published a very significant longitudinal study including 1,040 elderly type 2 diabetic patients followed for 12 to 24 months [9]. In that study, 164 of 954 patients without macroalbuminuria at baseline progressed at least one level from normo- or microalbuminuria to micro- or macroalbuminuria. After adjustment for other clinical covariates, ambulatory PP was a strong and independent predictor of albuminuria progression, above and beyond office BP. The study had considerable statistical power, due to a large number of participants and the employment of $24 \mathrm{~h}$ AMBP, whereas its limitations included the relatively short follow-up period of only 1 to 2 years, considering the fact that diabetic nephropathy typically evolves over a decade or more [31]. Moreover, albuminuria status was evaluated on the basis of a single urine sample, even though three samples are usually recommended due to the considerable intra-individual day-to-day variability of this key variable [21]. Finally, these important results from elderly participants (mean age around 71 years) cannot necessarily be extrapolated to other age groups with less arterial stiffness and, consequently, a less pronounced elevation of PP. In the present study, we confirm the results from the Palmas study and extrapolate them to a group of middle-aged (mean age 58 years) type 2 diabetic patients followed for 9.5 years with a more precise assessment of nephropathy status (based on three urine samples per patient at baseline as well as at follow-up).

Numerous previous studies have established the superiority of 24 h AMBP over conventional office BP measurement for the association with $[1,5,15,32,33]$ and prediction of hypertensive end-organ damage in diabetes $[9,34,35]$. Moran et al. found that office and $24 \mathrm{~h}$ systolic AMBP were independently associated with albuminuria in elderly type 2 diabetic patients [4]; however in the longitudinal study mentioned above [9], ambulatory PP predicted progression of albuminuria above and beyond office BP. In the present study, none of the office BP values had any significant predictive value for the progression of nephropathy, whereas $24 \mathrm{~h}$ systolic AMBP and PP values were strong predictors of nephropathy progression in type 2 diabetic patients. Obviously, the shortcomings of office BP measurement in the present study can be ascribed to lack of power, but it is striking that this commonly used diagnostic modality had no predictive value in a 9.5 year follow-up study in a high-risk group of type 2 diabetic patients. These results suggest that more widespread use of $24 \mathrm{~h}$ AMBP measurements could significantly improve our ability to identify patients at increased risk of developing microvascular complications.

In addition, use of $24 \mathrm{~h}$ AMBP as opposed to office BP measurement provides the opportunity to study diurnal BP fluctuations. In particular, focus has been directed towards a blunted nocturnal BP reduction ('non-dipping'), a pattern that has been consistently associated with diabetic vascular complications in previous studies [1, 10-17, 35]. In a 3 year follow-up of the same elderly type 2 diabetic patients mentioned above $[4,9]$, the investigators found that patients with a reversed diurnal BP rhythm (nocturnal BP 'risers') had an increased risk of nephropathy progression compared with patients with a normal reduction in BP during nighttime ('dippers'), whereas patients with a reduced nocturnal BP decline ('non-dippers') had an intermediate risk of progression [19]. Nocturnal BP rising was an independent predictor of albuminuria progression in the multivariate analysis, whereas non-dipping did not independently predict albuminuria progression. In the present study, we found that a reduced diastolic nocturnal BP decline was an independent predictor of nephropathy progression; moreover, we found a strong and intriguing additive effect of combining diastolic night:day BP ratio and $24 \mathrm{~h}$ PP. Thus, in the group of patients with diastolic night:day BP ratio and $24 \mathrm{~h}$ PP below the median, only one of 33 patients progressed, whereas 17 of 32 patients in the group with these $\mathrm{BP}$ variables equal to or above the median progressed to a more advanced nephropathy stage.

Several questions remain unanswered.

First, what are the underlying pathophysiological mechanisms connecting the haemodynamic abnormalities, elevated PP and blunted nocturnal BP decline, with the development of microvascular complications, in casu progression of nephropathy in type 2 diabetes? We have previously demonstrated strong associations between endothelial perturbation and both non-dipping [17] and elevated PP [5], suggesting that an 
enhanced level of endothelial cell activation could represent a link between these haemodynamic abnormalities and the development of microvascular complications in type 2 diabetes, possibly by promoting inflammation and atherosclerosis and by increasing the tendency of blood clotting. However, we were unable to make firm conclusions regarding causality due to the cross-sectional design of the studies.

Second, could pharmacological intervention against elevated PP or reduced nocturnal BP decline lead to a reduced incidence of microvascular complications? We have recently demonstrated that 12 months dual blockade with an angiotensin 2 receptor antagonist (candesartan) and an ACE inhibitor (lisinopril) was more effective in lowering $24 \mathrm{~h}$ ambulatory PP than monotherapy with high-dose lisinopril in type 2 diabetic patients [36]. However, it is as yet unknown whether this narrowing of PP induced by dual blockade of the renin-angiotensin system will translate into a long-term reduction in microvascular complications. Several researchers have demonstrated that it is possible to restore the normal circadian BP pattern in 'non-dipper's with selective antihypertensive therapy directed towards an elevated night BP [37-40]. Interestingly, this approach has been reported to reduce $24 \mathrm{~h}$ albumin excretion rate in microalbuminuric patients with essential hypertension, thus suggesting an increased organoprotective effect of reestablishing the normal diurnal BP rhythm [39]. These results are interesting and promising, but long-term intervention studies are needed to resolve whether antihypertensive treatment should be directed towards restoring the normal diurnal BP variation in 'non-dipping' patients and reducing an elevated PP.

The strengths of the present study include the long follow-up period of 9.5 years, the precise assessment of nephropathy status at baseline and follow-up, as well as the employment of $24 \mathrm{~h}$ AMBP measurement. There are several limitations to this study. First, the study was a clinically based observational study; hence, all types of pharmacological intervention were allowed during the follow-up period. Indeed, most patients received additional pharmacological (antihypertensive, lipid-lowering, antithrombotic etc.) therapy during this period, and we do not have the possibility to statistically correct for this intercurrent medication. However, during the follow-up period patients with high baseline BP levels would have been more likely to receive intensified antihypertensive therapy (including ACE inhibitors and angiotensin 2 receptor antagonists) than patients with low BP levels at baseline, thus reducing their risk of nephropathy progression and introducing a bias towards the null hypothesis. In spite of these pharmacological interventions during follow-up, high $24 \mathrm{~h} \mathrm{PP}$ and reduced diastolic night BP decline were strong predictors of nephropathy progression, suggesting that these variables are useful for risk assessment in everyday clinical practice. Second, the number of patients participating in the study was limited, thus limiting statistical power. As previously discussed, this could explain the lack of predictive value of office BP variables for nephropathy progression in the present study, whereas the very significant results for smoking, $24 \mathrm{~h}$ ambulatory PP and diastolic night:day BP ratio despite the limited size of the study indicate that these variables are strong and important predictors of this serious complication.

In the present 9.5 year observational study, $24 \mathrm{~h}$ ambulatory PP, impaired nocturnal diastolic BP decline and smoking were strong, independent predictors of nephropathy progression in type 2 diabetic patients. These potentially modifiable risk factors could represent important targets for pharmacological and non-pharmacological intervention aiming at reducing the incidence of this serious complication of type 2 diabetes.

Acknowledgements The following private and government foundations are acknowledged for financial support: The Beckett Foundation, The Sehested Hansen Foundation, The Jochum Jensen Memorial Grant and the Aarhus University Research Fund. The authors thank M. Møller and H. Hedegaard for their excellent technical assistance.

Duality of interest The authors declare that there is no duality of interest associated with this manuscript.

\section{References}

1. Knudsen ST, Poulsen PL, Hansen KW, Ebbehoj E, Bek T, Mogensen CE (2002) Pulse pressure and diurnal blood pressure variation: association with micro- and macrovascular complications in type 2 diabetes. Am J Hypertens 15:244-250

2. Knudsen ST, Bek T, Poulsen PL, Hove MN, Rehling M, Mogensen CE (2002) Macular edema reflects generalized vascular hyperpermeability in type 2 diabetic patients with retinopathy. Diabetes Care 25:2328-2334

3. Leitao CB, Canani LH, Polson PB, Molon MP, Pinotti AF, Gross JL (2005) Urinary albumin excretion rate is associated with increased ambulatory blood pressure in normoalbuminuric type 2 diabetic. Diabetes Care 28:1724-1729

4. Moran A, Palmas W, Pickering TG et al (2006) Office and ambulatory blood pressure are independently associated with albuminuria in older subjects with type 2 diabetes. Hypertension 47:955-961

5. Knudsen ST, Jeppesen P, Frederiksen CA et al (2007) Endothelial dysfunction, ambulatory pulse pressure, and albuminuria are associated in type 2 diabetic subjects. Diabet Med 24:911-915

6. Schram MT, Kostense PJ, Van Dijk RA et al (2002) Diabetes, pulse pressure and cardiovascular mortality: the Hoorn Study. J Hypertens 20:1743-1751

7. Nakano S, Konishi K, Furuya K et al (2005) A prognostic role of mean 24-h pulse pressure level for cardiovascular events in type 2 diabetic subjects under 60 years of age. Diabetes Care 28:95-100

8. Cockcroft JR, Wilkinson IB, Evans M et al (2005) Pulse pressure predicts cardiovascular risk in patients with type 2 diabetes mellitus. Am J Hypertension 18:1463-1467 
9. Palmas W, Moran A, Pickering T et al (2006) Ambulatory pulse pressure and progression of urinary albumin excretion in older patients with type 2 diabetes mellitus. Hypertension 48:301-308

10. Nielsen FS, Rossing P, Bang LE et al (1995) On the mechanisms of blunted nocturnal decline in arterial blood pressure in NIDDM patients with diabetic nephropathy. Diabetes 44:783-789

11. Hansen KW, Sorensen K, Christensen PD, Pedersen EB, Christiansen JS, Mogensen CE (1995) Night blood pressure: relation to organ lesions in microalbuminuric type 1 diabetic patients. Diabet Med 12:42-45

12. Berrut G, Fabbri P, Bouhanick B et al (1996) Decrease of nocturnal blood pressure in type II diabetic subjects with microalbuminuria. Arch Mal Coeur Vaiss 89:1041-1044

13. Nakano S, Ishii T, Kitazawa M, Kigoshi T, Uchida K, Morimoto S (1996) Altered circadian blood pressure rhythm and progression of diabetic nephropathy in non-insulin dependent diabetes mellitus subjects: an average three year follow-up study. J Investig Med $44: 247-253$

14. Mitchell TH, Nolan B, Henry M, Cronin C, Baker H, Greely G (1997) Microalbuminuria in patients with non-insulin-dependent diabetes mellitus relates to nocturnal systolic blood pressure. Am J Med 102:531-535

15. Poulsen PL, Bek T, Ebbehøj E, Hansen KW, Mogensen CE (1998) 24-h ambulatory blood pressure and retinopathy in normoalbuminuric IDDM patients. Diabetologia 41:105-110

16. Lurbe E, Redon J, Kesani A et al (2002) Increase in nocturnal blood pressure and progression to microalbuminuria in type 1 diabetes. N Engl J Med 347:797-805

17. Knudsen ST, Jeppesen P, Frederiksen CA et al (2007) Endothelial perturbation: a link between non-dipping and retinopathy in type 2 diabetes? J Am Soc Hypertension 1:208-215

18. Nakano S, Fukuda M, Hotta F et al (1998) Reversed circadian blood pressure rhythm is associated with occurrences of both fatal and nonfatal vascular events in NIDDM subjects. Diabetes 47:1501-1506

19. Palmas W, Pickering T, Teresi J et al (2008) Nocturnal blood pressure elevation predicts progression of albuminuria in elderly people with type 2 diabetes. J Clin Hypertens (Greenwich) 10:12-20

20. O'Brien E, Coats A, Owens P et al (2000) Use and interpretation of ambulatory blood pressure monitoring: recommendations of the British Hypertension Society. BMJ 320:1128-1134

21. Mogensen CE, Keane WF, Bennett PH et al (1995) Prevention of diabetic renal disease with special reference to microalbuminuria. Lancet 346:1080-1084

22. Brenner BM, Cooper ME, de Zeeuw D et al (2001) Effects of losartan on renal and cardiovascular outcomes in patients with type 2 diabetes and nephropathy. N Engl J Med 345:861-869

23. Lewis EJ, Hunsicker LG, Clarke WR et al (2001) Renoprotective effect of the angiotensin-receptor antagonist irbesartan in patients with nephropathy due to type 2 diabetes. N Engl J Med 345:851-860

24. Patel A, MacMahon S, Chalmers J et al (2007) Effects of a fixed combination of perindopril and indapamide on macrovascular and microvascular outcomes in patients with type 2 diabetes mellitus (the ADVANCE trial): a randomised controlled trial. Lancet 370:829-840
25. Benetos A, Safar M, Rudnichi A et al (1997) Pulse pressure: a predictor of long-term cardiovascular mortality in a French male population. Hypertension 30:1410-1415

26. Verdecchia P, Schillaci G, Borgioni C, Ciucci A, Pede S, Porcellati C (1998) Ambulatory pulse pressure: a potent predictor of total cardiovascular risk in hypertension. Hypertension 32:983988

27. Franklin SS, Khan SA, Wong ND, Larson MG, Levy D (1999) Is pulse pressure useful in predicting risk for coronary heart disease? The Framingham Heart Study. Circulation 100:354-360

28. Blacher J, Staessen JA, Girerd X et al (2000) Pulse pressure not mean pressure determines cardiovascular risk in older hypertensive patients. Arch Intern Med 160:1085-1089

29. Franklin SS, Larson MG, Khan SA et al (2001) Does the relation of blood pressure to coronary heart disease risk change with aging? The Framingham Heart Study. Circulation 103:1245-1249

30. Staessen JA, Thijs L, O'Brien ET et al (2002) Ambulatory pulse pressure as predictor of outcome in older patients with systolic hypertension. Am J Hypertens 15:835-843

31. Mogensen CE (2003) Microalbuminuria and hypertension with focus on type 1 and type 2 diabetes. J Intern Med 254:45-66

32. Poulsen PL, Ebbehoj E, Hansen KW, Mogensen CE (1997) 24-h blood pressure and autonomic function is related to albumin excretion within the normoalbuminuric range in IDDM patients. Diabetologia 40:718-725

33. Andersen NH, Poulsen SH, Poulsen PL et al (2005) Left ventricular dysfunction in hypertensive patients with type 2 diabetes mellitus. Diabet Med 22:1218-1225

34. Poulsen PL, Hansen KW, Mogensen CE (1994) Ambulatory blood pressure in the transition from normo- to microalbuminuria. A longitudinal study in IDDM patients. Diabetes 43:1248-1253

35. Astrup AS, Nielsen FS, Rossing P et al (2007) Predictors of mortality in patients with type 2 diabetes with or without diabetic nephropathy: a follow-up study. J Hypertens 25:2479-2485

36. Knudsen ST, Andersen NH, Poulsen SH et al (2008) Pulse pressure lowering effect of dual blockade with candesartan and lisinopril vs. high-dose ACE inhibition in hypertensive type 2 diabetic subjects: a CALM II Study post-hoc analysis. Am J Hypertens 21:172-176

37. Kario K, Schwartz JE, Pickering TG (2000) Changes of nocturnal blood pressure dipping status in hypertensives by nighttime dosing of alpha-adrenergic blocker, doxazosin: results from the HALT study. Hypertension 35:787-794

38. Hermida RC, Calvo C, Ayala DE et al (2005) Treatment of non-dipper hypertension with bedtime administration of valsartan. J Hypertens 23:1913-1922

39. Hermida RC, Calvo C, Ayala DE, Lopez JE (2005) Decrease in urinary albumin excretion associated with the normalization of nocturnal blood pressure in hypertensive subjects. Hypertension 46:960-968

40. Uzu T, Harada T, Namba T et al (2005) Thiazide diuretics enhance nocturnal blood pressure fall and reduce proteinuria in immunoglobulin A nephropathy treated with angiotensin II modulators. J Hypertens 23:861-865 